\title{
The Impact of Positive and Negative Spiritual Experiences on Distress and the Moderating Role of Mindfulness
}

\author{
Niko Kohls ${ }^{\mathrm{a}, \mathrm{c})}$, Harald Walach ${ }^{\mathrm{b}), \mathrm{c}}$ and George Lewith ${ }^{\mathrm{d})}$ \\ a) Generation Research Program, Human Science Centre \\ Ludwig-Maximilians-University Munich, Munich, Germany \\ E-mail: nkohls@grp.hwz.uni-muenchen.de \\ b) Division of Psychology, School of Social Sciences, The University of Northampton, \\ Northampton NNZ 7AL, UK \\ c) Brain, Mind and Healing Program, Samueli Institute, Alexandria, VA, USA \\ d) The University of Southampton, Community Clinical Sciences, UK
}

Received: 8 September 2008; accepted: 9 October 2008

\begin{abstract}
Summary
Both spiritual experiences and mindfulness as a psychological variable have been identified as components of wellbeing and health. As there is uncertainty about their relationship, we have investigated the impact of spiritual experiences and mindfulness as well as their interaction on distress in chronically ill patients. The unidimensional Daily Spiritual Experiences Scale (DSES), the multidimensional Exceptional Experiences Questionnaire (EEQ), the Freiburg Mindfulness Inventory (FMI), and the Brief Symptom Inventory (BSI) were administered to 109 chronically ill patients. Fifty-eight patients (53\%) reported regular and frequent spiritual or contemplative practice from different traditions over an average of 14.7 years $(S D=13.7)$. Patients with regular spiritual practice reported more positive spiritual experiences, were more mindful and less distressed $(\mathrm{p}<.001)$. A stepwise linear regression analysis revealed that the EEQ subscale "negative spiritual experiences" (NSE) was the most important single predictor for psychological distress $\left(\mathrm{R}^{2}=.38 ; \beta=.63\right)$. In contrast, both the EEQ subscale "positive spiritual experiences" as well as the DSES that also captures positives daily encounters with a transcendental realm or entity did not account for a significant amount of variance in distress. Further analysis of the regression model $\left(\mathrm{R}^{2}=.57\right)$, confirmed that NSE was still the largest predictor for distress $(\beta=.61)$ and that mindfulness $(\beta=-.38)$ and the interaction between mindfulness and NSE $(\beta=-.23)$ were the most important buffers protecting individuals from distress. Thus, mindfulness seems not only to be a
\end{abstract}

Harald Walach and Niko Kohls are sponsored by the Samueli Institute, Alexandria, VA, USA. George Lewith's post is supported by the Rufford Maurice Laing foundation. Alex Begg and Holly Malpass helped with data entry. 
clinically important protective factor for buffering generic distress, but particularly for distress derived from NSEs. This suggests that in addition to directly facilitating well-being and health by means of positive spiritual experiences, at least some form of regular spiritual or meditative techniques seem to endow an individual with a certain degree of resilience against negative spiritual experiences that is likely a consequence of increased mindfulness. If these findings are vindicated by further studies, spiritual experiences should not be conceived and measured as univariate but rather multivariate constructs.

\section{Keywords}

spirituality, mindfulness, spiritual experiences, distress

\section{Introduction}

Spirituality has been identified as a potential health resource that allows us to cope with illness and distress (Koenig, McCullough, \& Larson, 2001; Larson \& Larson, 2003). However, the specific pathways and models through which this may occur remain unclear (Batson, Schoenrade, \& Ventis, 1993; Seeman, Dubin, \& Seeman, 2003). To date empirical research has mostly focused on spiritual and religious attitudes, beliefs and practices, whereas spiritual, religious, transcendental or-to use an epistemologically more neutral termexceptional experiences and their impact on health have only been of minor interest (George, Larson, Koenig, \& McCullough, 2000).

We start from the assumption that a pivotal step towards revealing the pathways from spirituality to health is the distinction between direct intrapersonal effects stemming from exceptional and spiritual experiences as opposed to religious and spiritual beliefs or religious behaviour. We feel it is important to distinguish between positive and negative spiritual experiences, because spiritual experiences are neither predominantly positive nor do they have positive impact upon health by default. There is also a dark side of spirituality that needs to be acknowledged: Spiritual experiences are often associated with crises (Wardell \& Engebretson, 2006), and psychotic states frequently seem similar to states of spiritual and transcendent ecstasies (Lukoff, 1988; Lukoff, Lu, \& Turner, 1992; Lukoff, Lu \& Turner, 1998; Thalbourne, 1991).

For the sake of clarification, we have proposed the following working definitions (Kohls \& Walach, 2006). Exceptional Human Experiences is used as an umbrella term for experiences that touch on areas outside the common sense reality of our everyday world. Spiritual Experiences are a specific subcategory that can be considered to be experiences of a universal or comprehensive reality that need not necessarily be interpreted in a formal or traditional religious framework, but frequently such existing frameworks are used for interpreting 
these experiences. They are then termed Religious Experiences. Spiritual Practice can be construed as any regular activity such as prayer, meditation or forms of contemplation that is intended and designed to facilitate spiritual experiences. Thus, spirituality focuses primarily on experiences and insights, while religion can be regarded as a complex cultural and social framework, that tries to encapsulate, interpret and facilitate spiritual experiences.

Kohls and Walach suggest that the experiential side of spirituality and the associated regular spiritual or contemplative practice, may enhance specific psychological competencies which could improve health (Kohls, 2004; Kohls, Hack, \& Walach, 2008; Kohls \& Walach, 2006, 2007; Kohls, Walach, \& Wirtz, 2009). We have developed a multidimensional scale, the Exceptional Experiences Questionnaire (EEQ), which differentiates such exceptional experiences into positive, negative, psychopathological and visionary experiences (see measures section for details). In a previous study, we identified large differences in the prevalence of positive and negative spiritual experiences as well as their pathways to distress in two sociodemographically balanced non clinical samples of spiritually practicing and non practicing individuals (Kohls, 2004; Kohls \& Walach, 2007). Individuals practicing spiritually reported more positive and negative spiritual experiences and more visionary dream experiences, but no difference was found for psychopathological experiences (Kohls \& Walach, 2007). Those experiences accounted for 7\% of psychological distress overall, but for $36 \%$ of distress in individuals with no spiritual practice. A more sophisticated reanalysis of the data using structural equation modelling has corroborated this finding (Kohls, Walach \& Wirtz, 2009). While a simplistic interpretation would suggest that positive spiritual experiences are a resource of resilience against stress and of inner support, our recent studies suggest that the picture is more complicated. We found that if spiritual experiences are differentiated into positive and negative ones we can begin to understand their complex nature. It appears that their most powerful effectat least with regard to some aspects of wellbeing and health-is the potentially distressing nature of negative spiritual experiences involving ego-dissolution, deconstruction and destabilisation, while the beneficial impact of positive spiritual experiences seems to play-at least in direct comparison-only a minor role. An intersample comparison of the specific pathways revealed that the distress caused by negative spiritual experiences could be balanced by spiritual practice so they become better integrated and less threatening. Therefore, at least some forms of spiritual and meditative practices could be construed as the art of detachment such that the pathways from negative spiritual experiences inducing distress are partially suppressed. We believe that our findings 
have the following methodological implications, if they are corroborated in future studies.

1) Unidimensional Scales measuring only positive spiritual experiences such as the Daily Spiritual Experiences Scale (DSES; Underwoos \& Teresi, 2002; Underwood 2006; see measures section for details) seem to be inappropriate for scrutinizing the benefits of spiritual experiences for health, in the light of our finding, at least in some populations (Kohls, Walach, Wirtz, 2009).

2) We would expect stronger effects of negative spiritual experiences in individuals that are particularly prone to experiencing more deconstructive experiences, possibly as a natural consequence of their physical and mental situation such as chronically ill patients. This may be the reason why spirituality has always played an important role within palliative medicine.

Another possibility of understanding spirituality is through the psychological functions and processes associated with regular meditative and contemplative practice. Mindfulness is a central concept that has its roots in Buddhist spiritual practice and other meditative and contemplative traditions that actively strive for cultivating and developing a state of conscious and non-judgemental awareness (Brown \& Ryan, 2003). In psychological terms mindfulness may be understood as a mode of mental processing that focuses on the direct and immediate perception of the present moment with a state of open and receptive but non-judgemental awareness, voluntarily suspending evaluative cognitive feedback (Hayes \& Shenk, 2004). Mindfulness can systematically be trained (Davidson et al., 2003), and, correspondingly, practicing mindfulness, for example by means of meditation, may be regarded as a systematic venue for developing the state of mindfulness (Kabat-Zinn, 2005). Recent studies have shown that enhancing mindfulness through systematic training is associated with positive effects in a variety of well-being measures (Baer, 2003; Grossman, Schmidt, Niemann, \& Walach, 2004).

Shapiro and colleagues have recently proposed the IAA theory that assumes that three inseparable components of mindfulness intention (I), attention (A) and attitude (A) allow the transformation and the associated health effects to happen (Shapiro, Carlson, Astin \& Freedman, 2006). Their theory suggests that intentionally (I) attending (A) with openness and a non-judgmental attitude (A) leads to a significant shift in global perspective, which the authors 
have termed reperceiving. Through the process of mindfulness reperceiving allows an individual to detach from the current contents of consciousness and observe their moment-by-moment experiences with greater clarity and objectivity. Thus, within this theory reperceiving is understood as a meta-mechanism of action, which leads to a shift in perspective that overarches additional direct mechanisms that lead to change and positive outcome.

In order to shed more light on the pathways that drive the connection between spirituality and health, we consider it useful to combine the experiential aspect of spirituality with the functional aspect associated with the psychological construct of mindfulness. More specifically, we wanted to answer the question whether mindfulness changes the pathways of positive or negative spiritual experiences on distress in chronically ill patients. Given that mindfulness is considered to be a mechanism associated with detachment of the ego, it is more likely that this mechanism would functionally allow an individual to cope with negative spiritual experiences rather than profit from positive spiritual experiences. In order to empirically answer this question, we have investigated the relationship between exceptional and spiritual experiences, mindfulness and distress in chronically ill patients treated in an integrative medicine clinic.

\section{Methods}

\section{Participants}

The questionnaire battery, which consisted of the scales described below was administered to chronically ill patients that were randomly selected from a patient database within a single medically managed private integrative medicine clinic (Southampton UK). Inclusion criteria were recent treatment ( $<3$ years), age $>18$ years and a diagnosis of one of the three main disorders treated in that outpatient clinic: migraine, irritable bowel or chronic fatigue syndrome. Six hundred questionnaires were disseminated by post together with an introduction letter, a consent form and a pre-paid envelope for returning the survey. Forty-three letters could not be delivered. In total, 111 questionnaires were finally returned from the 600 sent together with a signed consent form, leading to an overall return rate of $18.5 \%$. Two questionnaires were not completely answered and were correspondingly excluded from the analysis. The sample consisted of 71 cases with chronic fatigue (65\%), 29 
$(27 \%)$ individuals with an irritable bowel syndrome as well as $9(8 \%)$ patients suffering from migraine. Participants were offered no reimbursement. Ethics approval was obtained from the University of Northampton ethics review board.

\section{Outcomes}

The Daily Spiritual Experience Scale (DSES) is a 16-item uni-dimensional instrument designed to measure frequency of positive spiritual experiences (Underwood, 2006; Underwood \& Teresi, 2002). The DSES assesses the perception of the connection with the transcendent as well as moments of interactions with the transcendent in daily life. Items (sample items: "I feel God's presence." and "I am spiritually touched by the beauty of creation.") focus on experience rather than beliefs or behaviours. Response options range from never or almost never (1) to many times a day (5). The psychometric properties are good (Cronbach's Alpha $=0.95$; test-retest reliability alpha $=0.92)$.

Exceptional Experiences Questionnaire (EEQ): A four-dimensional scale developed for measuring positive and negative spiritual experiences, psychopathological experiences and visionary dream experiences (Kohls, 2004; Kohls \& Walach, 2006; Kohls, Hack \& Walach, 2008). There exists a 57 item long and a 25 item short form. In this study, the 25-item short form of the EEQ was used, which shows good overall psychometric properties (Cronbach's alpha: $\alpha=.89$, test-retest reliability after 6 months $r=.85$ ) as well as acceptable properties for each factor: The four factors of the EEQ scale capture positive (7 items; $\alpha=0.88 ; r_{\text {test-retest }}=0.87$ ) and negative spiritual ( 7 items; $\alpha=0.81$; $\left.\mathrm{r}_{\text {test-retest }}=0.75\right)$ experiences as well as psychopathological experiences ( 7 items; $\alpha=0.67 ; r_{\text {test-retest }}=0.66$ ) and visionary dream experiences ( 4 items; $\alpha=0.89$; $\left.\mathrm{r}_{\text {test-retest }}=0.85\right)$. The questionnaire asks about the frequency of exceptional experiences as well as their current evaluation. The EEQ shows adequate discriminant validity with sense of coherence, social support and mental distress and convergent validity with transpersonal trust (Kohls, 2004; Kohls \& Walach, 2006). The four scales that were empirically corroborated by means of factor analyses (Kohls, 2004; Kohls \& Walach, 2006; Kohls, Hack \& Walach, 2008) can be described as follows:

1) Positive spiritual experiences: This factor embraces positive spiritual experiences of transcending the self as well as sensations of connectedness and unity with a transcendental entity or realm. Example items are 
"I am illumined by divine light and divine strength" and " $A$ higher being protects or helps me".

2) Negative spiritual experiences: The second factor describes experiences of deconstruction and ego loss as well as fearful sensations of isolation and loneliness that are frequently described in the mystical literature as a consequence of following a spiritual path. Example items are " $M y$ world-view is falling apart" and "A feeling of ignorance or not knowing overwhelms me".

3) Psychopathological experiences: The third factor embraces psychopathological experiences that predominantly fit into the psychotic and paranoid sphere. Example items are "I clearly hear voices, which scold me and make fun of me, without any physical causation" and "I am controlled by strange and alien forces".

4) Visionary dream experiences: The fourth factor relates to intensive dream type experiences. Two examples items are "I dream so vividly that my dreams reverberate while I am awake" and "I have meaningful dreams".

Freiburg Mindfulness Inventory (FMI) assesses awareness and nonjudgment of present moment experiences (Walach, Buchheld, Buttenmüller, Kleinknecht, \& Schmidt, 2006; Heidenreich, Ströhle, \& Michalak, 2006; Kohls, Sauer \& Walach, 2009). Sample items are "I am open to the experience of the present moment" and "I accept unpleasant experiences". The unidimensional 14 item short form (Cronbach's alpha $=.86$ ) was employed in this study which is a consistent and reliable short form of the scale.

Brief Symptom Index (BSI): The Symptom Checklist (SCL 90-R) is one of the most widely used self report screening instruments to briefly assess prevalent psychological disturbances using nine subscales (Derogatis \& Melisaratos, 1983). We used the abbreviated 53 item English short form that employs a frequency rating for common symptoms such as "Feeling no interest in things" or "Suddenly scared for no reasons" to assess, whether clinically relevant symptoms of distress are present. Many studies found quite different factor solutions within different population samples (Holi, Sammallahti, \& Aalberg, 1998; Schmitz et al., 2000), but there is consensus that the BSI is best viewed as a global measure of nonspecific distress or negative affect. We employed a stable indicator for general distress, the Global Severity Index (GSI). The GSI can be regarded a summary of the BSI, computed as the mean score of all 53 items of the BSI. 


\section{Statistical Analysis}

We used SPSS 11.0 for the statistical analysis of raw data and missing data were checked for systematic patterns. As we were interested in comparing sample means, only raw data were analyzed. For the sake of consistency, mean scores were computed for FMI, although sum scores have been suggested. Additionally, in order to avoid difficulties in data interpretation all scales have been rescaled to have the same orientation (i.e. ascending values are signifying increase in parameter). For estimating the impact of the EEQ factors and the DSES and FMI on psychological distress as measured with the Global Severity Index of the BSI, two independent stepwise linear regression analyses were computed, that investigated the main effects of the predictor variables as well as their respective interaction effect with mindfulness. Cases with missing values in any of the relevant variables were excluded from the regression analysis. All the variables were centered before they were submitted to the respective regression analysis and predictor variables were included if $\mathrm{p}<.05$ and excluded if $\mathrm{p}>.10$.

\section{Results}

\section{Sample Sociodemographics}

Sociodemographics for the patient sample are presented in Table 1:

Table 1. Sociodemographical data for subsamples

\begin{tabular}{lc}
\hline & Chronically ill patients \\
\hline $\mathbf{N}$ & 109 \\
Diagnosis & $71(65 \%)$ \\
Chronic Fatigue Syndrome & $29(27 \%)$ \\
Migraine & $9(8 \%)$ \\
Irritable Bowel & \\
Sex & $95(88 \%)$ \\
Women & $13(12 \%)$ \\
Men & 48.2 \\
Mean age & $(\mathrm{SD}=14.6)$ \\
Family status & $29(27 \%)$ \\
Single &
\end{tabular}


Table 1 (cont.)

\begin{tabular}{lc}
\hline & Chronically ill patients \\
\hline Married & $57(52 \%)$ \\
Divorced & $22(20 \%)$ \\
Widowed & $1(1 \%)$ \\
Own children & $66(61 \%)$ \\
Regular Spiritual Practice & $58(53 \%)$ \\
Life situation & \\
Living alone & $33(30 \%)$ \\
Living in parental home & $3(3 \%)$ \\
Living with a partner & $54(50 \%)$ \\
Living in a joint residence & $18(17 \%)$ \\
Denomination & \\
Catholic & $8(7 \%)$ \\
Protestant & $43(43 \%)$ \\
Baptist & $4(4 \%)$ \\
Buddhist & $3(3 \%)$ \\
Other & $21(20 \%)$ \\
No denomination & $25(22 \%)$ \\
Education & \\
No Formal Degree & $20(21 \%)$ \\
School & $4(4 \%)$ \\
Undergraduate & $15(16 \%)$ \\
Graduate & $55(59 \%)$ \\
\hline Not &
\end{tabular}

Note: Case numbers may not equal $\mathrm{N}=109$ as missing data is not included. Percentage figures in this table are rounded up to nearest whole if they are $>.5$ and rounded down if $<.5$; therefore cumulated cumulative percent values may slightly differ from $100 \%$.

Fifty-eight patients (53\%) reported regular spiritual or contemplative practice over 14.7 years $(S D=13.7)$ and the majority reported that they were either practicing "very often" $(\mathrm{N}=23 ; 41 \%)$ or "often" $(\mathrm{N}=15 ; 27 \%)$. Their practices originated from different traditions and included Buddhist meditation, Christian prayer and contemplation, Qi-Gong, Reiki, Transcendental and Quaker meditation, as well as different forms of Yoga. 


\section{Mean Scores}

Table 2 depicts sample means and standard deviations of the four scales for the full sample $(\mathrm{N}=109)$ as well as for those practicing $(\mathrm{N}=57)$ and non-practicing subsamples $(\mathrm{N}=52)$. Additionally the corresponding p-values for an independent samples t-test as well as Cohen's d are depicted.

Table 2. Mean scores (M) and standard deviation (SD) for the full sample and the spiritually practicing and non practicing subsample

\begin{tabular}{|c|c|c|c|c|c|c|c|c|}
\hline & $\begin{array}{r}\mathrm{F} \\
\mathrm{Sar} \\
(\mathrm{N}=\end{array}$ & $\begin{array}{l}\text { ll } \\
\text { ple }\end{array}$ & $\begin{array}{l}\text { Spiri } \\
\text { Pract } \\
(\mathrm{N}=\end{array}$ & $\begin{array}{l}\text { ually } \\
\text { cing } \\
\text { 57) }\end{array}$ & $\begin{array}{r}\text { Spir } \\
\mathrm{N} \\
\text { Prac } \\
(\mathrm{N}\end{array}$ & $\begin{array}{l}\text { ually } \\
\text { n } \\
\text { cing } \\
52)\end{array}$ & $\mathrm{p}^{*}$ & $\begin{array}{c}\text { Cohen's } \\
\mathrm{d}^{* *}\end{array}$ \\
\hline & M & SD & M & SD & M & SD & & \\
\hline $\begin{array}{l}\text { Daily Spiritual } \\
\text { Experiences Scales } \\
\text { (DSES) } \\
\text { Exceptional Experiences } \\
\text { Questionnaire (EEQ) }\end{array}$ & 3.33 & 1.27 & 3.94 & 1.15 & 2.62 & 1.02 & $<.001$ & 1.14 \\
\hline $\begin{array}{l}\text { Prevalence (Range: } 0-4 \text { ) } \\
\text { Positive Spiritual } \\
\text { Experiences }\end{array}$ & 1.27 & .99 & 1.87 & .91 & .61 & .56 & $<.001$ & 1.67 \\
\hline $\begin{array}{l}\text { Prevalence } \\
\text { Negative Spiritual } \\
\text { Experiences }\end{array}$ & .73 & .59 & .81 & .57 & .65 & .60 & .16 & 0.27 \\
\hline $\begin{array}{l}\text { Prevalence } \\
\text { Psychopathology }\end{array}$ & .28 & .36 & .28 & .30 & .28 & .41 & .96 & .00 \\
\hline $\begin{array}{l}\text { Prevalence } \\
\text { Visionary Dreams }\end{array}$ & 1.29 & .91 & 1.37 & .89 & 1.21 & .93 & .15 & .18 \\
\hline $\begin{array}{l}\text { Freiburg Mindfulness } \\
\text { Inventory (FMI) } \\
\text { (Range: } 1-4)\end{array}$ & 2.60 & .61 & 2.81 & .57 & 2.35 & .57 & $<.001$ & 0.81 \\
\hline $\begin{array}{l}\text { Global Severity Index } \\
\text { (Brief Symptom } \\
\text { Inventory) } \\
\text { (Range: } 0-4 \text { ) }\end{array}$ & .77 & .68 & .64 & .60 & .91 & .75 & .04 & -0.40 \\
\hline
\end{tabular}

Notes: Bold letters indicate significance at $\mathrm{p}<.001$ and italic letters at $\mathrm{p}<.05$.

${ }^{*} \mathrm{p}$ for an independent intersample samples t-test (non spiritually practicing vs. spiritually practicing)

** based on pooled standard deviation 
Those patients practicing spiritual or contemplative techniques reported more positive spiritual experiences (EEQ factor $1 ; \mathrm{t}=8.81 ; \mathrm{p}=<.001$ ), while no other significant differences were found for the remaining three factors of the EEQ. In addition, spiritually practicing patients reported higher scores of mindfulness (FMI; $\mathrm{t}=4.12 ; \mathrm{p}=<.001$ ) and lower scores in distress (GSI of the BSI; $\mathrm{t}=-2.07 ; \mathrm{p}=.04)$.

\section{Correlational Analysis}

The first order correlation matrix (Pearson's r) for the FMI; DSES; BSI and the four EEQ subscales are depicted in Table 3:

Table 3. First order correlations (Pearson's r, two-tailed)

\begin{tabular}{|c|c|c|c|c|c|c|c|}
\hline & $\begin{array}{c}\text { EEQ } \\
\text { Positive } \\
\text { Spiritual } \\
\text { Experiences }\end{array}$ & $\begin{array}{c}\text { EEQ } \\
\text { Negative } \\
\text { Spiritual } \\
\text { Experiences }\end{array}$ & $\begin{array}{c}\text { EEQ } \\
\text { Psychopathology }\end{array}$ & $\begin{array}{c}\text { EEQ } \\
\text { Visionary } \\
\text { Dreams }\end{array}$ & FMI & DSES & $\begin{array}{c}\text { BSIM } \\
\text { Global } \\
\text { Severity } \\
\text { Index }\end{array}$ \\
\hline $\begin{array}{l}\text { EEQ } \\
\text { Positive Spiritual } \\
\text { Experiences }\end{array}$ & & $\left..399^{(* *}\right)$ & $.23\left(^{*}\right)$ & $.30\left({ }^{* *}\right)$ & $.50(* *)$ & $.76(* *)$ & -.07 \\
\hline $\begin{array}{l}\text { EEQ } \\
\text { Negative Spiritual } \\
\text { Experiences }\end{array}$ & $\left..399^{(* *}\right)$ & & $.54(* *)$ & $.46\left(^{(* *}\right)$ & .03 & .07 & $\left..59^{* *}\right)$ \\
\hline $\begin{array}{l}\text { EEQ } \\
\text { Psychopathology }\end{array}$ & $.23\left(^{*}\right)$ & $.54(* *)$ & & $.37\left(^{* *}\right)$ & -.01 & .01 & $.29\left(^{* *}\right)$ \\
\hline $\begin{array}{l}\text { EEQ } \\
\text { Visionary Dreams }\end{array}$ & $.30\left(^{(* *}\right)$ & $.46\left(^{(* *}\right)$ & $.37\left(^{(* *}\right)$ & & .11 & .02 & $.23\left(^{*}\right)$ \\
\hline $\begin{array}{l}\text { FMI } \\
\text { DSES }\end{array}$ & $\begin{array}{l}.50(* *) \\
.76(* *)\end{array}$ & $\begin{array}{l}.03 \\
.07\end{array}$ & $\begin{array}{r}-.01 \\
.01\end{array}$ & $\begin{array}{l}.11 \\
.02\end{array}$ & $.42\left(^{* *}\right)$ & $.42(* *)$ & $\begin{array}{l}-.35\left(^{* *}\right) \\
-.18\end{array}$ \\
\hline $\begin{array}{l}\text { BSIM } \\
\text { Global Severity } \\
\text { Index }\end{array}$ & -.07 & $.59\left(^{(* *}\right)$ & $.29\left(^{* *}\right)$ & $.23\left(^{*}\right)$ & $-.35(* *)$ & -.18 & \\
\hline
\end{tabular}

Note: ${ }^{* *}$ Correlation is significant at the 0.01 level (2-tailed).

* Correlation is significant at the 0.05 level (2-tailed). 
Concerning the interfactor correlations of the EEQ, $r=.54$, the highest correlation, was found between the negative spiritual and psychopathological experiences factor.

With regard to external constructs, there is a high positive correlation between the DSES and the positive spiritual experiences scale $(\mathrm{r}=.76)$ and a moderate between the DSES and the FMI $(r=.42)$. The BSI is also positively correlated with the EEQ negative spiritual experiences $(\mathrm{r}=.59)$, the psychopathological experiences $(\mathrm{r}=.29)$ and the visionary dream experiences factor $(\mathrm{r}=.23)$; the FMI was found to be negatively correlated with the BSI $(\mathrm{r}=-.35)$.

\section{Linear Regression Analysis}

We then calculated two independent forward stepwise linear regression analyses with GSI of the BSI as dependent variable for cases with no missing data. In the first model, the four scales of the EEQ as well as the FMI were included as predictor variables; in the second model the DSES and the FMI were included. As the first factor of the EEQ and the DSES were highly correlated, in order to avoid problems of collinearity, the EEQ subscales and the DSES were not entered into the same model but separately computed. However, for both models, predictor variables were entered in two blocks: In the first model, in a first block the four EEQ scales as well as the FMI were entered as predictors thereby testing for main effects. In a second block, the interaction term of the FMI with the four EEQ-subscales was included in order to test for potential interaction effects between experiential dimensions of spirituality and mindfulness. In the second model, in the first block the DSES and FMI were included, and in the second block the interaction term between DSES and FMI.

Table 4 depicts all steps of the multivariate regression analysis as well as the corresponding change in $\mathrm{R}^{2}$ for both models.

The first model of the stepwise regression analysis yielded three steps. In the first step, only the EEQ subfactor "negative spiritual experiences" was entered into the regression equation $\left(\mathrm{R}^{2}=.389 ; \beta_{\text {Negativespiritualexp. }}=.63\right)$. In the second step, in addition to negative spiritual experiences $\left(\beta_{\text {Negativespiritualexp. }}=.64\right)$, mindfulness $\left(\beta_{\text {Mindfulness }}=-.37\right)$ was included as a second predictor. $\mathrm{R}^{2}$ was thereby increased by .137 leading to a total $\mathrm{R}^{2}=.523$. In a third step, the interaction between negative spiritual experiences and mindfulness was included as a third

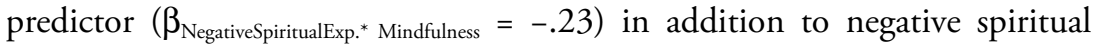
experiences $\left(\beta_{\text {NegativespiritualExp. }}=.61\right)$ and mindfulness $\left(\beta_{\text {Mindfulness }}=-.38\right)$. This final step led to an additional increase of .052 in $\mathrm{R}^{2}$, which resulted in a total $\mathrm{R}^{2}$ of .572 . 
Table 4. Stepwise linear regression analysis

\begin{tabular}{llll}
\hline $\begin{array}{l}\text { Adjusted } \mathrm{R}^{2} \\
\text { (F-statistic) }\end{array}$ & Change in $\mathrm{R}^{2}$ & Predictor Variable & Beta \\
\hline
\end{tabular}

\section{Model 1}

Step

1. $\quad .389\left(\mathrm{~F}_{1,102}=\right.$

66.60)

2.

$.523\left(\mathrm{~F}_{2,101}=\right.$

57.41)

3. $\quad .572\left(\mathrm{~F}_{3,100}=\right.$ 46.89)

Model 2

Step

1 .

$.106\left(\mathrm{~F}_{1,105}=\right.$

13.61)
Negative Spiritual Experiences

.63

(EEQ factor 2)

Negative Spiritual Experiences

.64

(EEQ factor 2)

Mindfulness (FMI)

$-.37$

Negative Spiritual Experiences

.61

(EEQ factor 2)

Mindfulness (FMI)

$-.38$

Interaction Negative Spiritual

Experiences \& Mindfulness

Mindfulness (FMI)

Notes: All models and predictor variables significant at $\mathrm{p}<=0.001$

Stepwise method was used and predictor variables were entered in two blocks for both models:

Model 1: block 1: EEQ factors 1-4, FMI; block 2: Interaction EEQ 1-4* FMI

Model 2: block 1: DSES, FMI; block 2: Interaction DSES * FMI

Bold letters indicate significance at $\mathrm{p}<.01$ and italic letters at $\mathrm{p}<.05$.

The second model yielded only one step, where mindfulness was entered into the regression equation $\left(R^{2}=.106 ; \beta_{\text {NegativespiritualExp. }}=-.34\right)$.

The comparison of the two models revealed that the largest predictor for distress is negative spiritual experiences. In contrast, positive spiritual experiences have no significant protective effect on distress. Mindfulness however, seems to be not only a generic buffer for general distress as it is indicated by the main effect for model 1 and model 2, but as model 1 suggests that it may also act as a specific suppressor for distress derived from negative spiritual experiences.

\section{Discussion}

We have found significant differences between spiritually practicing and non practicing chronically ill patients suffering from chronic fatigue, migraine and 
irritable bowel. Patients practicing a form of spiritual practice reported more positive spiritual experiences, described themselves as more mindful and less distressed than those patients with no spiritual practice.

In a second step, first order correlation analyses were employed in order to investigate the relationship between exceptional and spiritual experiences, mindfulness and distress. Mindfulness was only found to be significantly correlated with positive spiritual experiences (both measured by means of the EEQ factor 1 and the DSES) as well as negatively with distress; in contrast no significant relationship was found between positive spiritual experiences and distress. However, a positive relationship with distress was found for negative spiritual experiences (EEQ factor 2) and psychopathological experiences (EEQ factor 3). The first order correlation between negative spiritual experiences as they were measured with the EEQ and psychological distress as measured with the BSI found in this study shows that these two constructs share $35 \%$ of variance in the full sample. Thus, it seems at first glance that, although there is apparently some overlap between negative spiritual experiences and psychological distress, these should be considered independent constructs with some common ground.

In a third step, regression analyses were employed in order to scrutinize the amount of variance explained in distress by exceptional experiences and mindfulness both by means of their main and interaction effects. Based on our previously observed differences in the pathways from negative spiritual experiences to distress in non clinical populations of spiritually practising and non practising individuals (Kohls \& Walach, 2007; Kohls, Walach \& Wirtz, 2009) we particularly predicted relevant effects in people who are prone to distress such as those with chronic illness. However, a more detailed pictureparticularly concerning the interaction between exceptional experiences and mindfulness_-becomes possible by means of a stepwise regression analysis with spiritual experiences and mindfulness entered as independent variables and distress as dependent variable. The respective analyses revealed that negative spiritual experience was the most substantial and significant predictor of distress explaining 39\% of the variance in our sample of patients with chronic illness. We also found a negative main effect pathway from mindfulness to distress which replicated our earlier findings (Walach et al., 2006). This suggests that negative spiritual experiences are the most distressing experiences, whereas mindfulness acted as a generic buffer against distress. However, we additionally discovered an interaction effect between negative spiritual experiences and mindfulness indicating that mindfulness seems to additionally act as 
a specific suppressor protecting against distress derived from deconstructive experiences associated with spirituality. This finding can shed light on the intrapersonal mechanisms associated with mindfulness. If one learns to be present with a non-judgmental attitude, the mode of perception is systematically geared to a less ego-centered perspective and correspondingly experiences of ego loss may be less threatening. It is thereby noteworthy to mention that, by combining main effects of the experiential side of spirituality with the psychological function of mindfulness as well as their interaction effect, we have been able to explain $57 \%$ of distress in chronically ill patients.

In contrast, positive spiritual experiences measured with EEQ and the DSES were not associated with distress. Thus, the effect of positive spiritual experience on distress and related health outcomes appears to be of less importance than the effect of negative spiritual experiences. The assumption that positive spiritual experiences have substantial direct beneficial effects on health would appear to be incorrect, as it seems - at least in the light of our findingsrather to be the case that they are indirectly exhibiting augmenting health, and possibly by enhancing mindfulness (George, Larson, Koenig, \& McCullough, 2000). It is however noteworthy to recall that many of the instruments used to measure spiritual experience are designed as unidimensional constructs only recording positive spiritual experiences, such as the Daily Spiritual Experiences Scale (Underwood, 2006; Underwood \& Teresi, 2002). Consequently we should be careful not to focus exclusively on promoting positive spiritual experience as a direct route to wellbeing and also-at least from a clinical perspective-consider the option that some forms of spiritual practice may indirectly help augmenting well-being by minimizing the potentially destructive effects of negative spiritual experiences through protective spiritual practices that enhance mindfulness. Future studies should thus strive to measure spiritual experiences as multi- and not only unidimensional constructs.

Our data suggest that individuals with higher mindfulness scores may be able to manage their negative spiritual experiences more easily. This may be because those individuals assess deconstructive experiences more positively (Kohls \& Walach, 2006) or it may be that individuals practicing some form of meditation seem to be able to alter their personal psychological model so they can dissociate their present self awareness from their long term 'self image' (Farb et al., 2007), possibly creating resilience that sustains them through negative spiritual experiences. We suggest that a lack of spiritual practice and consequently a lack of mindfulness should be considered a risk factor for individuals who are particularly prone to experiencing distress. 
Our study has some limitations: the non-experimental design means that we had to rely on cross-sectional convenience samples, naturally restricting our ability to control for confounding variables. Thus, although complex and multi-faceted variables such as spirituality have a tendency to evade experimental manipulation, we acknowledge that to test our hypothesis definitively controlled prospective longitudinal randomised trials with matched populations are necessary. We were unable to collect longitudinal data in this study so the directionality of the pathways and mechanisms could not be conclusively defined. Although this could not be definitively addressed in this study, extant longitudinal data in non-clinical populations suggests that the causal pathway to distress seems to be triggered by negative spiritual experiences rather than the other way round (Kohls \& Walach, 2007).

The response rate for our study was only $18.5 \%$ so there is a possibility that our sample is biased, possibly because spiritually inclined individuals may be more likely to participating in studies associated with spirituality. Thus, the result that $53 \%$ of our population exercises a form of mindfulness or spiritual practice may likely be an overestimation, at least when compared to the general population. However, it has been repeatedly shown that spiritual attitudes and practices are associated with those attending integrative medicine practices so equally this may be a true reflection of the population seeking integrative medical care (Dessio et al., 2004; Petry \& Finkel, 2004).

Nevertheless, we believe that the data presented in this paper together with our earlier findings (Kohls \& Walach, 2007; Kohls, Wirtz \& Walach, 2009) allows us to draw some tentative conclusions: we suggest that a higher degree of mindfulness seems to compensate, not only for general distress, but also for distress derived from experiences of negative spiritual experiences in chronically ill patients. In the light of our findings, spirituality does not appear to improve health and wellbeing directly but a lack of spiritual, meditative or contemplative practice and correspondingly a lack of mindfulness may possibly be regarded as an important risk factors for psychological distress.

\section{References}

Baer, R. A. (2003). Mindfulness training as a clinical intervention: A conceptual and empirical review. Clinical Psychology: Science and Practice, 10, 125-143.

Batson, C. D., Schoenrade, P., \& Ventis, W. L. (1993). Religion and the individual: a social-psychological perspective: Oxford University Press.

Brown, K. W., \& Ryan, R. M. (2003). The benefits of being present: Mindfulness and its role in psychological well-being. Journal of Personality and Social Psychology, 84, 822-848. 
Davidson, R. J., Kabat-Zinn, J., Schumacher, J., Rosenkranz, M., Muller, D., Santorelli, S. F., et al. (2003). Alterations in brain and immune function produced by mindfulness meditation. Psychosomatic Medicine, 65, 564-570.

Derogatis, L., \& Melisaratos, N. (1983). The Brief Symptom Inventory: An introductory report. Psychological Medicine, 13(3), 595-605.

Dessio, W., Wade, C., Chao, M., Kronenberg, F., Cushman, L. E., \& Kalmuss, D. (2004). Religion, spirituality, and healthcare choices of African-American women: Results of a national survey. Ethnicity \& Disease, 14(2), 189-197.

Farb, N. A. S., Segal, Z. V., Mayberg, H., Bean, J., McKeon, D., Fatima, Z., et al. (2007). Attending to the present: mindfulness meditation reveals distinct neural modes of self-reference. Social Cognitive and Affective Neuroscience, 2(4), 313-322.

George, L. K., Larson, D. B., Koenig, H. G., \& McCullough, M. E. (2000). Spirituality and health: What we know, what we need to know. Journal of Social and Clinical Psychology, 19, 102-116.

Grossman, P., Schmidt, S., Niemann, L., \& Walach, H. (2004). Mindfulness based stress reduction and health: A meta-analysis. Journal of Psychosomatic Research, 37, 35-43.

Hayes, S. C., \& Shenk, C. (2004). Operationalizing Mindfulness Without Unnecessary Attachments. Clinical Psychology: Science and Practice, 11(3), 249-254.

Heidenreich, T., Ströhle, G., \& Michalak, J. (2006). Achtsamkeit: Konzeptuelle Aspekte und Ergebnisse zum Freiburger Achtsamkeitsfragebogen. Verhaltenstherapie, 16, 33-40.

Holi, M., Sammallahti, P., \& Aalberg, V. (1998). A Finnish validation study of the SCL-90. Acta Psychiatrica Scandinavica, 97, 42-46.

Kabat-Zinn, J. (2005). Coming to our senses. New York: Hyperion.

Koenig, H., McCullough, M., \& Larson, D. (Eds.). (2001). Handbook of religion and health. New York: Oxford University Press.

Kohls, N. (2004). Aussergewöhnliche Erfahrungen-Blinder Fleck der Psychologie? Eine Auseinandersetzung mit aussergewöhnlichen Erfahrungen und ihrem Zusammenhang mit geistiger Gesundheit. Münster: Lit-Verlag.

Kohls, N., Hack, A., \& Walach, H. (2008). Measure the unmeasurable by ticking boxes and actually opening Pandoras Box? Mixed Methods Research as a useful tool for thinking out of the box while investigating exceptional human experiences. The Archive for the Psychology of Religion, 30, 155-187.

Kohls, N., Sauer, S., \& Walach, H. (2009). Facets of mindfulness-Results of an online study investigating the Freiburg mindfulness inventory. Personality and Individual Differences 46 (2), 224-230.

Kohls, N., \& Walach, H. (2006). Exceptional experiences and spiritual practice- A new measurement approach. Spirituality and Health International, 7(3), 125-150.

Kohls, N., \& Walach, H. (2007). Psychological distress, experiences of ego loss and spirituality: Exploring the effects of spiritual practice. Social Behavior and Personality, 35(10), 1301-1316.

Kohls, N., Walach, H., \& Wirtz, M. (2009). The relationship between spiritual experiences, transpersonal trust, social support, and sense of coherence and mental distress-a comparison 
of spiritually practising and non-practising samples. Mental Health, Religion \& Culture, 12(1), $1-23$.

Larson, D. B., \& Larson, S. S. (2003). Spirituality's potential relevance to physical and emotional health: A brief review of quantitative research. Journal of Psychology and Theology, 31, $37-51$.

Lukoff, D. (1988). Transpersonal perspectives on manic psychosis: Creative, visionary, and mystical states. Journal of Transpersonal Psychology, 20, 111-139.

Lukoff, D., Lu, F., \& Turner, R. (1992). Toward a more culturally sensitive DSM-IV. Psychoreligious and psychospiritual problems. Journal of Nervous and Mental Disease, 180, 673-682.

Lukoff, D., Lu, F., \& Turner, R. (1998). From spiritual emergency to spiritual problem: The transpersonal roots of the new DSM IV category. Journal of Humanistic Psychology, 38, 21-50.

Petry, J. J., \& Finkel, R. (2004). Spirituality and choice of health care practitioner. The Journal of Alternative and Complementary Medicine, 10(6), 939-945.

Schmitz, N., Hartkamp, N., Kruse, J., Franke, G. H., Reister, G., \& Tress, W. (2000). The Symptom Check-List-90-R (SCL-90-R): A German validation study. Quality of Life Research, 9, 185-193.

Seeman, T. E., Dubin, L. F., \& Seeman, M. (2003). Religiosity/Spirituality and health: A critical review of the evidence for biological pathways. American Psychologist, 58, 53-63.

Segal, Z. V., Williams, J. M. G., \& Teasdale, J. D. (2002). Mindfulness-based cognitive therapy for depression: A new approach to preventive relapse. New York: Guilford Press.

Shapiro, S. L., Carlson, L. E., Astin, J. A., \& Freedman, B. (2006). Mechanisms of mindfulness. Journal of Clinical Psychology, 62(3), 373-386.

Thalbourne, M. A. (1991). The psychology of mystical experience. Exceptional Human Experience, 9, 168-183.

Underwood, L. G. (2006). Ordinary spiritual experience: Qualitative research, interpretive guidelines, and population distribution for the Daily Spiritual Experience Scale. Archive for the Psychology of Religion, 28:1 (2006), 181-218.

Underwood, L. G., \& Teresi, J. (2002). The Daily Spiritual Experience Scale: Development, theoretical description, reliability, exploratory factor analysis, and preliminary construct validity using health-related data. Annals of Behavioral Medicine, 24(1), 22-33.

Walach, H., Buchheld, N., Buttenmüller, V., Kleinknecht, N., \& Schmidt, S. (2006). Measuring mindfulness - the Freiburg Mindfulness Inventory (FMI). Personality and Individual Differences, 40, 1543-1555.

Wardell, D. W., \& Engebretson, J. C. (2006). Taxonomy of spiritual experiences. Journal of Religion and Health, 45(2), 215-233. 